\title{
Multimodalidad, emoción y publicidad. Un estudio empírico sobre Youtube
}

\section{Multimodality, emotion and advertising. An empirical study about Youtube}

\author{
Diego Calderón-Garrido \\ Profesor de la Facultad de Educación \\ (Universidad Internacional de La Rioja)
}

Josep Gustems-Carnicer

Director del Departamento de Didáctica de las Ciencias Sociales, la Educación Musical, la Educación Física y la Educación Visual y Plástica

(Universidad de Barcelona)

\section{Carolina Martín-Piñol}

Profesora Ayudante Doctor en el Departamento de Didáctica de las Ciencias Sociales, la Educación Musical, la Educación Física y la Educación Visual y Plástica (Universidad de Barcelona)

Fecha de recepción: 28 de noviembre de 2016

Fecha de revisión: 12 de abril de 2017

Fecha de publicación: 1 de julio de 2017

Para citar este artículo: Calderón-Garrido, D., Gustems-Carnicer, J. y Martín-Piñol, C. (2017): Multimodalidad, emoción y publicidad. Un estudio empírico sobre Youtube, Icono 14, volumen 15 (2), pp. 25-48. doi: 10.7195/ri14.v15i2.1041 


\section{ARTÍCULOS DE INVESTIGACIÓN}

\section{Resumen}

La publicidad es un instrumento de seducción en el que la música actúa como refuerzo en la atracción que el futuro usuario o consumidor siente por un producto, organización o servicio. En este trabajo se muestran los resultados de un estudio empírico realizado en la Universidad de Barcelona donde se han analizado las emociones provocadas por la música y las imágenes en una muestra formada por los 10 spots publicitarios más vistos en la plataforma Youtube en el año 2014. Para ello se ha contado con la participación de 31 estudiantes de Comunicación Audiovisual que los han visualizado en tres momentos distintos y randomizados, primero solo imagen, después, solo el audio y, en tercer lugar, el audiovisual completo. Para analizar las emociones provocadas se ha utilizado un instrumento de medida inspirado en el 2DES (Two Dimensional Emotion Space) y el Emotion Space Lab. Los resultados señalan tipos distintos de respuesta emocional según el canal perceptivo empleado, y su aportación al contenido emocional de los spots. Se señalan las formas de intermodalidad preferidas por los participantes en la muestra analizada. Asimismo, se constata la eficacia de los parámetros musicales y sonoros en el contenido emocional (tempo, intensidad, timbre, silencios, voces, estilos, etc.), corroborando así estudios previos en este sentido.

Palabras clave: Música - Emoción - Youtube - Anuncio - Multimodalidad

\section{Abstract}

Advertising is seduction tool in which music acts as a reinforcement in the attraction that the future user will feel about a product, organization or service. This paper presents the results of an empirical study conducted at the University of Barcelona, the emotions evoked by music and images have been analysed out of a sample consisting of the 10 most played advertising spots on the Youtube platform in 2014. For this, the help of 31 Image \& Sound Media students has been key, for they have viewed and randomized them in three different moments; on a first phase, only images were displayed; afterwards, they only listened to the sound; and thirdly, they viewed everything together. For the analysis of the emotions evoked after the viewing, a measurement tool based on 2DES (Two Dimensional Emotions Space) was 
used, as well as the Emotion Space Lab. The results point at different feedback at an emotion level, depending on the perception channel used, and its contribution regarding the emotional content. The intermodal manifestations preferred by the participants pointed out. The efficiency of the musical and sound parameters in the emotional content is determined (tempo, intensity, tone, silences, voices, styles, etc.), which would confirm previous studies in this field.

Key Words: Music - Emotion - Youtube - Spot - Multimodality

\section{Introducción}

\subsection{La publicidad}

La publicidad es una forma de venta y de construcción de marca, un espacio comunicativo basado en la búsqueda de medios para conseguir que alguien pase a ser usuario de un producto o un servicio, incluso llegando a cambiar sus opiniones, valores o juicios previos (Collelldemont, 2008). Para ello, se informa de sus beneficios y se motiva a su compra o su uso. En este proceso intervienen numerosas disciplinas tales como psicología, sociología, diseño, antropología, economía, imagen, narrativa o música. La publicidad se ha convertido en un engranaje capaz de mover sectores empresariales enteros, vinculando e incluyendo la afectividad en nuestro día a día (Gustems \& Calderón, 2014a).

Si bien en la era industrial el propósito de la publicidad era la venta de productos o la promoción de servicios, en la actualidad esta orientación ha derivado hacia el amor por las marcas y la creación de nuevos estilos de vida. Así pues, las marcas han pasado a tener identidad propia, asociada a estereotipos de personas que puedan sentirse identificadas con dichas marcas. La publicidad esconde cierta ilusión de felicidad, solitaria y envidiosa, ligada al objeto y a su posesión. Como espectadores, asistimos con frecuencia a campañas donde se anuncia un ideal inalcanzable que se simplifica y se pone al alcance del consumidor, a priori desinteresado, para que acabe por interesarle (Lipman \& Sharp, 1996). 


\section{ARTÍCULOS DE INVESTIGACIÓN}

Para conseguir todo esto, la publicidad utiliza estímulos racionales, pero sobre todo emocionales, pues generalmente lo que provoca la acción no es el raciocinio sino aquellos símbolos ligados al deseo: las emociones no crean contrargumentos. Por tanto, la publicidad se ocupa de describir las características racionales de un producto (lo que hace, su función, formas de uso...), las sensoriales (forma, envoltorio, aspecto, aroma, tacto, gusto...), y las emocionales. Mientras que el producto apunta a lo racional, la marca lo hace a lo emocional (Nardone \& Salvini, 2006). Si una marca logra inducir en el cerebro del consumidor la emoción adecuada -siguiendo los descubrimientos del neuromarketing- consigue fidelizarle durante un largo tiempo, identificándose con un determinado concepto, una estética concreta e incluso una experiencia sensorial (Sánchez, 2013).

\subsection{La publicidad en YouTube}

Internet y las redes sociales están cambiando algunos de los paradigmas publicitarios, multiplicando las posibilidades de llegar a sus usuarios potenciales (Madinaveitia, 2010). Con los avances actuales en las tecnologías, Internet desarrolla campañas de publicidad interactiva, un paso más allá respecto a la clásica publicidad para TV de carácter lineal, con inicio y final predeterminados por el emisor, donde el receptor no puede ejercer ninguna interacción sobre el mensaje. Conceptos tales como Banner Ads -páginas web que aparecen dentro de la propia página que estamos visitando- y sus diferentes versiones en función del dónde y cómo aparecen son comunes entre los publicistas, ofreciendo nuevas posibilidades en las propias páginas web o a través de las diferentes Ventanas emergentes. Lo que sí que parece claro es que estos soportes digitales ya son cotidianos en el ámbito publicitario.

En nuestro caso, nos centraremos en la publicidad del emblemático portal YouTube: Broadcast Yourself (http://www.youtube.com) o simplemente YouTube, tal como se le conoce popularmente. Este portal, creado en 2005 y adquirido posteriormente en 2006 por Google, permite subir y compartir videoclips mediante Internet, sitios Web, dispositivos móviles, e-mail y blogs, a la vez que encontrar vídeos sobre hobbies e intereses personales, ver acontecimientos y eventos actuales, e incluso descubrir cosas inusuales. Es decir, permite al usuario ser creador 
y receptor de los contenidos (Bañuelos, 2009), lo que se traduce en que cada minuto se suben a la plataforma más de 100 horas de vídeo. En consecuencia, no es de extrañar que, por ejemplo, solo en España ya en 2012 la página contase con aproximadamente 13,5 millones de usuarios cada mes (Lavado, 2013). En la actualidad hay más de mil millones de usuarios a nivel mundial, lo que supone una visualización de unas 6.000 millones de horas de vídeos al mes (según los datos obtenidos de YouTube).

Como cualquier lector podrá imaginarse, este público potencial ejerce un enorme atractivo para la publicidad. De hecho, las estadísticas de YouTube afirman que los ingresos de las empresas publicitadas a través de este canal aumentaron un 50 por ciento durante los tres años posteriores a iniciar la publicidad. Por tanto, es frecuente que cuando un usuario realice la búsqueda de un vídeo aparezca, además de los típicos banners que podemos encontrar en cualquier página, otro vídeo publicitario antes de empezar la reproducción deseada. No en vano, el portal se sustenta, principalmente, por los ingresos derivados de la publicidad (Larrañaga \& Ruiz, 2009).

Además, el interesado en publicitarse en YouTube puede elegir toda una serie de posibilidades a la hora de emitir su anuncio: qué países, qué horarios, asociado a qué criterios de búsqueda, etc., permitiendo focalizarse al target al cual se quiere acceder. En este sentido, la elección de dicho público potencial guarda los mismos criterios que la publicidad tradicional (Gustems \& Calderón, 2014a).

En definitiva, podemos afirmar que la publicidad en YouTube tiene unas características diferenciadoras que, si bien permiten que la publicidad que hasta ahora aparecía en otros medios audiovisuales pueda estar en la red, hayan aparecido nuevos modelos más acordes con esta plataforma, dando cabida a anunciantes poco comunes hasta ahora (Oliva, 2012). La publicidad audiovisual recoge las últimas tendencias sociales y corrientes creativas que circulan en los medios. Por eso los spots más recientes pueden ser un claro ejemplo de la actual disolución de fronteras entre distintos formatos audiovisuales (Fraile, 2012). 


\section{ARTÍCULOS DE INVESTIGACIÓN}

\subsection{Imagen y sonido en la publicidad de YouTube}

La experiencia visual que tiene un sujeto ante la publicidad que puede ofrecerle un canal como YouTube se corresponde físicamente con una estimulación, un bombardeo de imágenes por parte del susceptible consumidor, que queda expuesto a su contemplación mecánica (Camarero, 2009). Este espectador observa dicha publicidad con más o menos interés, pero ésta es capturada irremediablemente por su retina, en un sinfín de imágenes basadas en un conjunto de relatos, lo que Acaso denomina como "metanarrativa visual" (2006: 30). Pero el carácter cognitivo de la percepción de la imagen es condicionado por la memoria visual (Villafañe, 2006). La imagen de la publicidad solamente habrá llegado a su objetivo si la experiencia visual se refleja en una modificación emocional, conductual o verbal que el sujeto pueda mostrar tras visualizar la misma.

En este contexto, los individuos, deslumbrados por el espectáculo, nos sumergimos en una existencia pasiva aspirando solo a adquirir la mayor cantidad de productos posibles. Para que el consumidor se convierta en tal, es necesario estimularle visualmente y para crear este impulso irracional, paradójico, perverso, la utilización del lenguaje visual es la clave (Acaso, 2009). La realidad de este formato de publicidad es que nos presenta ante nosotros un mundo que ha cambiado y que ha sido substituido por el mundo como imagen.

Si pensamos en el audio, los nuevos modelos de publicidad en YouTube nos acercan, en muchas ocasiones, más al género de los cortometrajes que al de la propia publicidad. A pesar de esto mantienen muchas similitudes con la publicidad audiovisual tradicional, en especial el hecho de que más del 97 por ciento de los anuncios contengan música (Sedeño, 2011).

Nos encontramos con bandas sonoras para anuncios que mantienen los tres actos clásicos de la trama argumental: presentación, nudo y desenlace. En cualquier caso, los parámetros observados son muy parecidos a los ya descritos inicialmente por Gustems (2005) con diferentes situaciones relacionales: uso de los silencios como separación entre escenas y para preparar el packshot o presentación de la marca; cambios de intensidad para evitar saturación entre voces y música, ayudan- 
do a destacar las imágenes; uso estereotipado de algunos instrumentos musicales; uso generalizado de acordes consonantes y modo mayor, utilizando las disonancias para captar la atención; uso de ruidos con intención de contextualizar, descriptivos y realistas; uso de voces habladas masculinas o femeninas, según el target, sector productivo y contexto de compra; uso de músicas e instrumentos tradicionales con marcado sesgo cultural; y el uso de estilos y géneros musicales en función de las características sociodemográficas del público objetivo. Además, podemos utilizar la misma clasificación que se realiza en los audiovisuales tradicionales según su aplicación, distinguiendo entre música diegética, incidental, etc. En cualquier caso, el uso de la música de la publicidad en YouTube persigue el mismo objetivo que en la publicidad tradicional: "favorecer de forma decisiva los procesos de memorización de la marca y su imagen" (Santacreu, 2002, p. 268).

\subsection{Emociones en los audiovisuales}

Las emociones que provocan los audiovisuales son un aspecto ampliamente investigado por la importancia que estas tienen en todos los implicados: productores y receptores. No cabe duda de que tanto la música (Juslin \& Sloboda, 2001), las imágenes (Messaris, 1994) como la conjunción de ambas (Eder, 2008) nos afectan profundamente.

La emoción es generada como respuesta a un acontecimiento interno o externo, como serían las interrelaciones sociales, los pensamientos o las sensaciones propioceptivas. De esta forma estamos ante tres tipos de respuesta emocional que se combinan: neurofisiológica, conductual y cognitivo verbal, que a su vez pueden expresarse según dos dimensiones principales: valencia (bienestar/malestar) y arousal (relajante/activante) (Russell, 1980).

A lo largo del tiempo se han intentado clasificar las emociones según estos dos parámetros, que combinados darían lugar a cuatro grandes tendencias emocionales: la felicidad relajante (bienestar con poca activación), la alegría (bienestar con mucha activación), la tristeza (malestar con poca activación) y la ira (malestar con mucha activación) (Diener \& Emmonts, 1984). De esta forma, las emociones que despierten los anuncios en los espectadores vendrán enmarcadas por el bienestar y la excitación que nos hacen sentir, y de cómo estos factores se conjuguen entre sí 


\section{ARTÍCULOS DE INVESTIGACIÓN}

(Percy \& Rosenbaum-Elliott, 2016). Así pues, cada anuncio tendrá su propio balance entre estos parámetros en función de su objetivo; por ejemplo un spot sobre un parque de atracciones probablemente incentive el bienestar y la activación, mientras que uno que intente concienciar sobre las consecuencias de los accidentes de tráfico nos producirá malestar y una activación media.

\subsection{Multimodalidad}

El análisis multimodal (Gustems \& Calderón, 2014b) es una herramienta que nos permitirá analizar estos anuncios, ya que la música y el sonido no solo acompañarán, sino que enfatizarán todo lo que la imagen proponga, siendo necesarios diseños sonoros muy elaborados que contemplen diversos estados de ánimo, ritmos diferenciados, cambios de tempo, silencios prolongados, etc. Así pues, podemos hablar de bandas sonoras que encajan a la perfección con las imágenes, o bien de imágenes diseñadas para una música o paisaje sonoro concreto.

A pesar de que cada sujeto pueda tener distintas preferencias perceptivas por un modo de comunicación más visual, auditivo o cinestésico (Bandler \& Grinder, 1982), en el proceso de creación audiovisual intervienen distintos técnicos y artistas, con roles, formación y puntos de vista completamente diferentes, que tratan de armonizar los elementos visuales (texto escrito, imágenes, vídeos...) con los sonoros (música, diálogos, narraciones...). De esta forma, el texto escrito ya no es el único protagonista, sino que funciona como complemento para potenciar el mensaje creado mediante una red interrelacionada de otros lenguajes que le dan significado (Krees \& van Leeuwen, 2001).

Así, para entender el significado de un spot de YouTube se tendrán en cuenta todos los modos de comunicación empleados, y que no deberían ser estudiados de manera aislada, ya que están estrechamente conectados entre sí. No en vano, uno de los interrogantes más antiguos en psicología experimental concierne a la naturaleza de las interacciones entre modalidades sensoriales (por ejemplo, vista y oído); es decir, las posibles prioridades o jerarquías entre los sentidos cuando proveen información simultánea, ya sea coincidente o contradictoria. La información visual y auditiva, pues, pueden reforzarse mutuamente, contradecirse o modificar una a la otra (Vines, Krumhansl, Wanderley \& Levitin, 2006). 
Por este motivo, el objetivo de este estudio es conocer cómo la música y la imagen influyen en los aspectos emocionales (activación y bienestar) de los diez anuncios más vistos en YouTube en el año 2014. Para ello, se estudiará el efecto que dichos anuncios producen en cada uno de los canales perceptivos (visión y audición) por separado y conjuntamente, en un grupo de jueces. De esta forma podremos saber si en esta nueva tipología publicitaria la interrelación multimodal planteada funciona igual que en la publicidad tradicional.

\section{Metodología}

\subsection{La muestra}

Para realizar este estudio se ha escogido una muestra formada por los 10 anuncios más vistos a nivel internacional en la plataforma de YouTube durante el año 2014. En la siguiente tabla se resumen los principales aspectos de cada uno de los anuncios (ver tabla 1).

\begin{tabular}{|c|c|c|c|c|c|c|}
\hline & $\begin{array}{c}\text { Marca y } \\
\text { título }\end{array}$ & $\begin{array}{l}\mathrm{N}^{\circ} \text { de } \\
\text { visitas }\end{array}$ & Duración & $\begin{array}{c}\text { Resumen } \\
\text { argumental }\end{array}$ & $\begin{array}{c}\text { Aspectos } \\
\text { visuales más } \\
\text { destacados }\end{array}$ & $\begin{array}{l}\text { Aspectos sonoros } \\
\text { más destacados }\end{array}$ \\
\hline 1 & $\begin{array}{l}\text { Nike } \\
\text { Winter } \\
\text { Ways }\end{array}$ & $\begin{array}{l}98,4 \\
\text { mill. }\end{array}$ & $4^{\prime} 12^{\prime \prime}$ & $\begin{array}{l}\text { Futbol callejero } \\
\text { que se convierte } \\
\text { en profesional. }\end{array}$ & $\begin{array}{l}\text { Sucesión de } \\
\text { imágenes a } \\
\text { gran velocidad }\end{array}$ & $\begin{array}{l}\text { Ruidos de los perso- } \\
\text { najes y el público. } \\
\text { Canción rock incidental, } \\
\text { compás binario, pre- } \\
\text { existente, tempo rápido }\end{array}$ \\
\hline 2 & $\begin{array}{l}\text { Nike } \\
\text { The Last } \\
\text { Game }\end{array}$ & $\begin{array}{l}73,3 \\
\text { mill. }\end{array}$ & $5^{\prime} 28^{\prime \prime}$ & $\begin{array}{l}\text { Los protagonistas } \\
\text { son jugadores de } \\
\text { fútbol reales y } \\
\text { los antagonistas } \\
\text { clones }\end{array}$ & $\begin{array}{l}\text { Película de } \\
\text { animación con } \\
\text { dos ambientes } \\
\text { muy diferentes: } \\
\text { fuera y dentro } \\
\text { del campo }\end{array}$ & $\begin{array}{l}\text { En la primera parte una } \\
\text { banda sonora musi- } \\
\text { cal que acompaña los } \\
\text { diálogos. } \\
\text { En la segunda, canción } \\
\text { rock incidental preexis- } \\
\text { tente, compás binario, } \\
\text { tempo rápido y ruidos } \\
\text { del público }\end{array}$ \\
\hline
\end{tabular}




\section{ARTÍCULOS DE INVESTIGACIÓN}

\begin{tabular}{|c|c|c|c|c|c|c|}
\hline & $\begin{array}{c}\text { Marca y } \\
\text { título }\end{array}$ & $\begin{array}{l}\mathrm{N}^{0} \text { de } \\
\text { visitas }\end{array}$ & Duración & $\begin{array}{l}\text { Resumen } \\
\text { argumental }\end{array}$ & \begin{tabular}{|c|} 
Aspectos \\
visuales más \\
destacados
\end{tabular} & $\begin{array}{l}\text { Aspectos sonoros } \\
\text { más destacados }\end{array}$ \\
\hline 3 & $\begin{array}{l}\text { Budweiser } \\
\text { Puppy } \\
\text { Love }\end{array}$ & $\begin{array}{l}53,4 \\
\text { mill. }\end{array}$ & $1^{\prime}$ & $\begin{array}{l}\text { Un cachorro se } \\
\text { escapa continua- } \\
\text { mente de la casa } \\
\text { de adopción para } \\
\text { ver a un caballo }\end{array}$ & $\begin{array}{l}\text { Sucesión de es- } \\
\text { cenas bucólicas } \\
\text { en una granja }\end{array}$ & $\begin{array}{l}\text { Sonidos de animales. } \\
\text { Canción incidental, } \\
\text { popular, preexistente, } \\
\text { compás binario, tempo } \\
\text { medio }\end{array}$ \\
\hline 4 & $\begin{array}{l}\text { Always } \\
\text { Like a } \\
\text { girl }\end{array}$ & $\begin{array}{l}53,3 \\
\text { mill. }\end{array}$ & $3^{\prime} 19^{\prime \prime}$ & $\begin{array}{l}\text { Invita a la re- } \\
\text { flexión de cómo } \\
\text { las personas } \\
\text { actuamos cuando } \\
\text { se nos dice } \\
\text { "hazlo como una } \\
\text { chica" }\end{array}$ & $\begin{array}{l}\text { Imágenes en } \\
\text { un plato de } \\
\text { televisión. } \\
\text { Varias personas } \\
\text { realizando acti- } \\
\text { vidades físicas }\end{array}$ & $\begin{array}{l}\text { En la primera parte, } \\
\text { diálogos y ruidos de } \\
\text { los movimientos. En la } \\
\text { segunda parte, música } \\
\text { instrumental pop, in- } \\
\text { cidental, tempo medio, } \\
\text { original de carácter } \\
\text { épico, compás binario. } \\
\text { Es el vídeo que pre- } \\
\text { senta más silencios } \\
\text { musicales y en que } \\
\text { la música está a un } \\
\text { volumen considerable- } \\
\text { mente más bajo que los } \\
\text { diálogos. }\end{array}$ \\
\hline 5 & $\begin{array}{l}\text { Devil's } \\
\text { Due } \\
\text { Baby } \\
\text { attack }\end{array}$ & $\begin{array}{l}48,4 \\
\text { mill. }\end{array}$ & $1^{\prime} 49^{\prime \prime}$ & $\begin{array}{l}\text { Basado en la pe- } \\
\text { lícula que anun- } \\
\text { cia. Un muñeco } \\
\text { de bebé en una } \\
\text { carrito asusta } \\
\text { en diferentes } \\
\text { escenarios }\end{array}$ & $\begin{array}{l}\text { Diferentes esce- } \\
\text { narios en varias } \\
\text { calles de Nueva } \\
\text { York }\end{array}$ & $\begin{array}{l}\text { Sonidos propios de la } \\
\text { ciudad y gritos de los } \\
\text { viandantes. Música, ins- } \\
\text { trumental, Trash metal, } \\
\text { compás binario, tempo } \\
\text { medio }\end{array}$ \\
\hline 6 & \begin{tabular}{|l} 
Duracell \\
Trust \\
your \\
Power
\end{tabular} & $\begin{array}{l}22,7 \\
\text { mill. }\end{array}$ & $2^{\prime}$ & $\begin{array}{l}\text { Apela al valor del } \\
\text { esfuerzo a través } \\
\text { de los recuerdos } \\
\text { de un jugador de } \\
\text { futbol americano }\end{array}$ & $\begin{array}{l}\text { Diferentes } \\
\text { escenarios de- } \\
\text { portivos en los } \\
\text { que el jugador } \\
\text { ha entrenado, } \\
\text { casi siempre de } \\
\text { noche }\end{array}$ & $\begin{array}{l}\text { Voz en off del propio } \\
\text { deportista y sonidos de } \\
\text { las acciones que reali- } \\
\text { za. Música instrumental } \\
\text { original, incidental, de } \\
\text { tempo medio, com- } \\
\text { pás binario y carácter } \\
\text { épico. }\end{array}$ \\
\hline
\end{tabular}


ARTÍCULOS DE INVESTIGACIÓN

\begin{tabular}{|c|c|c|c|c|c|c|}
\hline & $\begin{array}{c}\text { Marca y } \\
\text { título }\end{array}$ & $\begin{array}{l}\mathrm{N}^{0} \text { de } \\
\text { visitas }\end{array}$ & Duración & $\begin{array}{l}\text { Resumen } \\
\text { argumental }\end{array}$ & $\begin{array}{c}\text { Aspectos } \\
\text { visuales más } \\
\text { destacados }\end{array}$ & $\begin{array}{l}\text { Aspectos sonoros } \\
\text { más destacados }\end{array}$ \\
\hline 7 & $\begin{array}{l}\text { Samsung } \\
\text { Galaxi } \\
\text { Note }\end{array}$ & $\begin{array}{l}22,1 \\
\text { mill. }\end{array}$ & $1^{\prime}$ & $\begin{array}{l}\text { Relato con } \\
\text { imágenes de las } \\
\text { características } \\
\text { del teléfono }\end{array}$ & $\begin{array}{l}\text { Imágenes del } \\
\text { teléfono y un } \\
\text { primer primerí- } \\
\text { simo plano de } \\
\text { una mano que } \\
\text { lo usa }\end{array}$ & $\begin{array}{l}\text { Voz en off. Acompaña- } \\
\text { miento instrumental, } \\
\text { original, notas cortas } \\
\text { de orquesta de cuerda } \\
\text { a tempo medio, compás } \\
\text { binario. }\end{array}$ \\
\hline 8 & $\begin{array}{l}P \& G \\
\text { Thank } \\
\text { you, } \\
\text { mom }\end{array}$ & $\begin{array}{l}19,7 \\
\text { mill. }\end{array}$ & $2^{\prime}$ & $\begin{array}{l}\text { Diseñado para los } \\
\text { Juegos Olímpi- } \\
\text { cos de Sochi. } \\
\text { Múltiples caídas } \\
\text { de personas } \\
\text { desde que son } \\
\text { bebés hasta que } \\
\text { han llegado a ser } \\
\text { deportistas olím- } \\
\text { picos, siempre } \\
\text { con el apoyo de } \\
\text { sus madres }\end{array}$ & $\begin{array}{l}\text { Varios esce- } \\
\text { narios, tanto } \\
\text { deportivos } \\
\text { como dentro } \\
\text { de casas, pero } \\
\text { siempre con } \\
\text { colores fríos y } \\
\text { nieve de fondo }\end{array}$ & $\begin{array}{l}\text { Sonidos de caídas y } \\
\text { aplausos al final. Mú- } \\
\text { sica incidental, pre- } \\
\text { existente, con carácter } \\
\text { épico, tempo rápido y } \\
\text { compás binario }\end{array}$ \\
\hline 9 & $\begin{array}{l}\text { Budwei- } \\
\text { ser } \\
\text { Friends } \\
\text { are } \\
\text { waiting }\end{array}$ & $\begin{array}{l}19,5 \\
\text { mill. }\end{array}$ & $1^{\prime}$ & $\begin{array}{l}\text { Un cachorro cree } \\
\text { que su dueño lo } \\
\text { ha abandonado } \\
\text { y se entristece, } \\
\text { pero finalmente } \\
\text { el dueño vuelve }\end{array}$ & $\begin{array}{l}\text { Sucesión rápida } \\
\text { de imágenes, } \\
\text { casi todas den- } \\
\text { tro de una casa }\end{array}$ & $\begin{array}{l}\text { Sonidos del perro y el } \\
\text { dueño. Música preexis- } \\
\text { tente, pop, incidental, } \\
\text { compás binario, tempo } \\
\text { medio, con cambios } \\
\text { bruscos que se corres- } \\
\text { ponden con los senti- } \\
\text { mientos del perro }\end{array}$ \\
\hline 10 & $\begin{array}{l}\text { Heine- } \\
\text { ken } \\
\text { The Pa- } \\
\text { yphone }\end{array}$ & $\begin{array}{l}13,8 \\
\text { mill. }\end{array}$ & $1^{\prime} 42^{\prime \prime}$ & $\begin{array}{l}\text { Cámara oculta } \\
\text { que graba a per- } \\
\text { sonas que reci- } \\
\text { ben una llamada } \\
\text { en una cabina } \\
\text { pública que les } \\
\text { invita a cruzar } \\
\text { la calle y entrar } \\
\text { en un bar, donde } \\
\text { se convierten en } \\
\text { protagonistas de } \\
\text { un espectáculo } \\
\text { de humor }\end{array}$ & $\begin{array}{l}\text { Escenas de } \\
\text { la casa desde } \\
\text { donde llaman, } \\
\text { la calle donde } \\
\text { está la cabina y } \\
\text { del interior del } \\
\text { bar }\end{array}$ & $\begin{array}{l}\text { Voces en primer plano } \\
\text { de la persona que lla- } \\
\text { ma, sonido de teléfono } \\
\text { y de la calle, y aplau- } \\
\text { sos de la gente del } \\
\text { bar. Música incidental, } \\
\text { original, tempo rápido, } \\
\text { compás binario con } \\
\text { carácter de aventura }\end{array}$ \\
\hline
\end{tabular}

Tabla 1: Principales características de la muestra de anuncios 


\section{ARTÍCULOS DE INVESTIGACIÓN}

\subsection{Procedimiento}

Todos los anuncios fueron visualizados y escuchados por 31 estudiantes del Grado de Comunicación Audiovisual de la Universidad de Barcelona (24 mujeres y 7 hombres) que hicieron el papel de jueces. Para ello, se eligieron tres momentos distintos con dos semanas de diferencia entre cada uno de ellos, proyectando en orden aleatorio los vídeos. Primero se procedió a la visualización sin audio, en la segunda fase la escucha sin imagen $\mathrm{y}$, finalmente, el audiovisual completo.

En cada una de las ocasiones, para analizar las emociones provocadas se utilizó un instrumento de medida inspirado en el 2DES (Two Dimensional Emotion Space) y el Emotion Space Labe (Schubert, 1999). De esta forma, cada uno de los estudiantes, individualmente, señaló un punto por cada anuncio en una hoja cuadriculada con dos ejes de coordenadas en forma de cruz. El eje horizontal correspondía al grado de activación sensorial (arousal) y el vertical a la valencia (bienestar/malestar) que cada anuncio le produjo (ver figura 1).

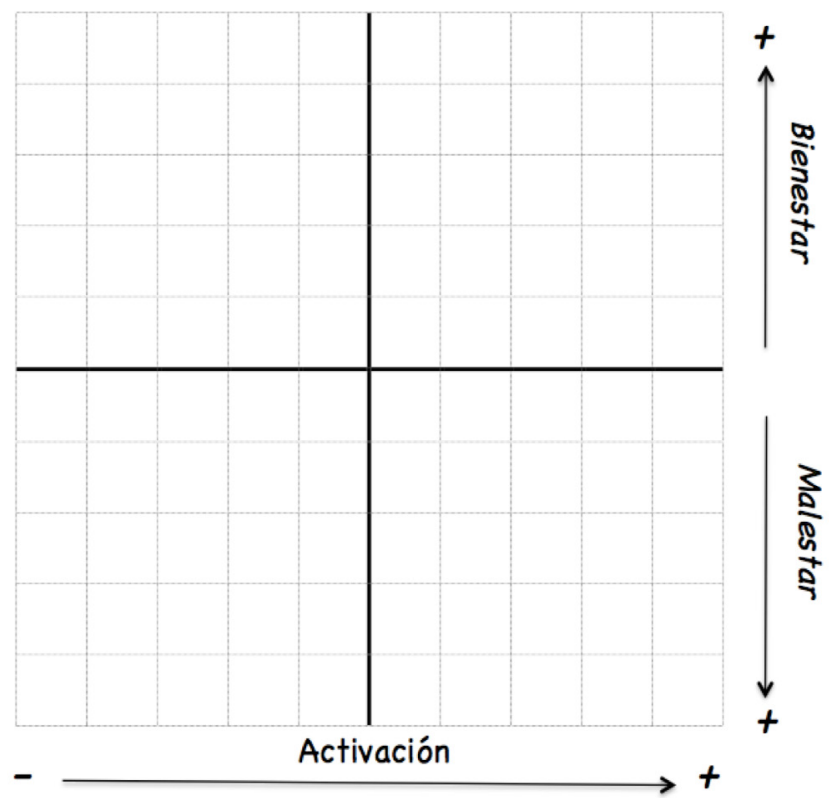

Figura 1: Modelo gráfico 2DES, adaptado a nuestra investigación 
Para su posterior análisis, a cada punto marcado se le otorgó un valor de dos coordenadas. De esta forma el punto 0,0 correspondería al de mínima activación y máximo malestar, el punto 5,5 sería el centro de la cruz y el punto 10,10 correspondería al de máxima activación y máximo bienestar.

Los resultados obtenidos fueron analizados posteriormente con el programa estadístico SPSS (Statistical Package for the Social Sciences), versión 21.0.

\section{Resultados}

En la tabla 2 se muestran las medias y desviaciones estándar (SD) de las respuestas obtenidas respecto la activación y el bienestar en cada fase del proceso (solo visión, solo audición, y visionado con audio), de cada uno de los vídeos, y la media total de cada fase (ver tabla 2).

\begin{tabular}{|c|c|c|c|c|c|c|}
\hline & \multicolumn{2}{|c|}{ Solo visión } & \multicolumn{2}{c|}{ Solo audio } & \multicolumn{2}{c|}{ Visión y audio } \\
\cline { 2 - 7 } & Activación & Bienestar & Activación & Bienestar & Activación & Bienestar \\
\hline Vídeo 1 & $\begin{array}{c}7,58 \\
(\mathrm{SD}=1,46)\end{array}$ & $\begin{array}{c}6,69 \\
(\mathrm{SD}=1,72)\end{array}$ & $\begin{array}{c}8,60 \\
(\mathrm{SD}=0,76)\end{array}$ & $\begin{array}{c}6,02 \\
(\mathrm{SD}=1,19)\end{array}$ & $\begin{array}{c}7,38 \\
(\mathrm{SD}=1,63)\end{array}$ & $\begin{array}{c}6,32 \\
(\mathrm{SD}=1,64)\end{array}$ \\
\hline Vídeo 2 & $\begin{array}{c}7,40 \\
(\mathrm{SD}=1,74)\end{array}$ & $\begin{array}{c}5,74 \\
(\mathrm{SD}=1,53)\end{array}$ & $\begin{array}{c}7,84 \\
(\mathrm{SD}=1,58)\end{array}$ & $\begin{array}{c}4,79 \\
(\mathrm{SD}=1,92)\end{array}$ & $\begin{array}{c}6,67 \\
(\mathrm{SD}=2,16)\end{array}$ & $\begin{array}{c}5,94 \\
(\mathrm{SD}=1,85)\end{array}$ \\
\hline Vídeo 3 & $\begin{array}{c}5,79 \\
(\mathrm{SD}=2,14)\end{array}$ & $\begin{array}{c}7,68 \\
(\mathrm{SD}=1,41)\end{array}$ & $\begin{array}{c}3,03 \\
(\mathrm{SD}=2,23)\end{array}$ & $\begin{array}{c}6,35 \\
(\mathrm{SD}=2,56)\end{array}$ & $\begin{array}{c}5,95 \\
(\mathrm{SD}=1,92)\end{array}$ & $\begin{array}{c}7,79 \\
(\mathrm{SD}=1,26)\end{array}$ \\
\hline Vídeo 4 & $\begin{array}{c}4,73 \\
(\mathrm{SD}=2,70)\end{array}$ & $\begin{array}{c}6,37 \\
(\mathrm{SD}=2,15)\end{array}$ & $\begin{array}{c}3,24 \\
(\mathrm{SD}=2,75)\end{array}$ & $\begin{array}{c}8,27 \\
(\mathrm{SD}=0,70)\end{array}$ & $\begin{array}{c}5,95 \\
(\mathrm{SD}=2,55)\end{array}$ & $\begin{array}{c}7,45 \\
(\mathrm{SD}=1,80)\end{array}$ \\
\hline Vídeo 5 & $\begin{array}{c}7,06 \\
(\mathrm{SD}=1,94)\end{array}$ & $\begin{array}{c}4,18 \\
(\mathrm{SD}=2,55)\end{array}$ & $\begin{array}{c}8,23 \\
(\mathrm{SD}=1,16)\end{array}$ & $\begin{array}{c}2,02 \\
(\mathrm{SD}=2,53)\end{array}$ & $\begin{array}{c}6,68 \\
(\mathrm{SD}=2,36)\end{array}$ & $\begin{array}{c}4,30 \\
(\mathrm{SD}=2,56)\end{array}$ \\
\hline Vídeo 6 & $\begin{array}{c}5,66 \\
(\mathrm{SD}=2,59)\end{array}$ & $\begin{array}{c}5,60 \\
(\mathrm{SD}=1,72)\end{array}$ & $\begin{array}{c}3,66 \\
(\mathrm{SD}=2,82)\end{array}$ & $\begin{array}{c}5,30 \\
(\mathrm{SD}=2,92)\end{array}$ & $\begin{array}{c}6,32 \\
(\mathrm{SD}=2,00)\end{array}$ & $\begin{array}{c}6,37 \\
(\mathrm{SD}=1,34)\end{array}$ \\
\hline
\end{tabular}


38 | Diego Calderón-Garrido, Josep Gustems-Carnicer y Carolina Martín-Piñol

\section{ARTÍCULOS DE INVESTIGACIÓN}

\begin{tabular}{|c|c|c|c|c|c|c|}
\hline & \multicolumn{2}{|c|}{ Solo visión } & \multicolumn{2}{|c|}{ Solo audio } & \multicolumn{2}{|c|}{ Visión y audio } \\
\hline & Activación & Bienestar & Activación & Bienestar & Activación & Bienestar \\
\hline Vídeo 7 & $\begin{array}{c}2,51 \\
(S D=2,09)\end{array}$ & $\begin{array}{c}4,77 \\
(S D=1,59)\end{array}$ & $\begin{array}{c}3,21 \\
(S D=1,87)\end{array}$ & $\begin{array}{c}5,90 \\
(S D=1,24)\end{array}$ & $\begin{array}{c}3,73 \\
(S D=2,02)\end{array}$ & $\begin{array}{c}5,10 \\
(S D=1,23)\end{array}$ \\
\hline Vídeo 8 & $\begin{array}{c}8,24 \\
(S D=1,20)\end{array}$ & $\begin{array}{c}8,48 \\
(S D=1,71)\end{array}$ & $\begin{array}{c}5,01 \\
(S D=2,44)\end{array}$ & $\begin{array}{c}5,16 \\
(S D=1,69)\end{array}$ & $\begin{array}{c}7,08 \\
(S D=2,56)\end{array}$ & $\begin{array}{c}8,73 \\
(S D=1,28)\end{array}$ \\
\hline Vídeo 9 & $\begin{array}{c}4,53 \\
(S D=2,55)\end{array}$ & $\begin{array}{c}7,45 \\
(S D=1,58)\end{array}$ & $\begin{array}{c}5,67 \\
(S D=1,60)\end{array}$ & $\begin{array}{c}8,18 \\
(S D=0,93)\end{array}$ & $\begin{array}{c}5,21 \\
(S D=2,13)\end{array}$ & $\begin{array}{c}7,70 \\
(S D=1,60)\end{array}$ \\
\hline Vídeo 10 & $\begin{array}{c}4,48 \\
(S D=2,06)\end{array}$ & $\begin{array}{c}6,00 \\
(S D=1,51)\end{array}$ & $\begin{array}{c}8,05 \\
(S D=1,07)\end{array}$ & $\begin{array}{c}4,40 \\
(S D=2,15)\end{array}$ & $\begin{array}{c}6,79 \\
(S D=1,64)\end{array}$ & $\begin{array}{c}6,41 \\
(S D=1,52)\end{array}$ \\
\hline $\begin{array}{l}\text { Medias } \\
\text { totales }\end{array}$ & $\begin{array}{c}5,80 \\
(S D=1,78)\end{array}$ & $\begin{array}{c}6,48 \\
(S D=1,36)\end{array}$ & $\begin{array}{c}5,93 \\
(S D=2,14)\end{array}$ & $\begin{array}{c}5,30 \\
(S D=1,97)\end{array}$ & $\begin{array}{c}6,18 \\
(S D=1,06)\end{array}$ & $\begin{array}{c}6,61 \\
(S D=1,33)\end{array}$ \\
\hline
\end{tabular}

Tabla 2: Puntuaciones obtenidas en cada vídeo (medias y desviaciones estándar), según modo perceptivo y dimensión emocional

Tal como podemos observar, en el caso de la activación, el rango de puntuaciones se sitúa entre 8,24 y 2,51 en el visionado sin audio, entre 8,60 y 3,21 en la audición sin imágenes, y entre 7,38 y 3,73 en el visionado con audio. En el caso del bienestar, el rango está entre 8,48 y 4,18 en el visionado sin audio, entre 8,27 y 2,02 en el audio sin imágenes, y entre 8,73 y 4,30 en el visionado con audio. Además, la media nos muestra como, por separado, el sonido activa algo más que la imagen $(5,93$ frente a 5.80), mientras que la visión sola proporciona bastante más bienestar que el audio solo $(6,48$ frente a 5,30). En el visionado con audio, la media es 6,18 en activación y 6,61 en bienestar, lo que nos indica que la muestra de anuncios analizada produce una activación y un bienestar positivos, aunque moderados.

No se han encontrado diferencias estadísticas en función del sexo de los jueces, excepto en el caso del cuarto vídeo en el que se detecta una diferencia estadísticamente significativa en el bienestar de la audición sin visionado $(t=2,608 ; p=0,014)$. 
El análisis de la totalidad de los datos obtenidos $(n=310)$ muestra múltiples correlaciones entre cada uno de los parámetros de los diferentes vídeos. Así pues, y centrándonos en las puntuaciones medias, las correlaciones más significativas son:

- en la visión sin sonido, la activación correlaciona directamente con el bienestar $r s=0,286(p<0,001)$,

- en el sonido sin visión, la activación correlaciona inversamente con el bienestar $r s=-0,341(p<0,001)$,

- en el visionado con audio, la activación correlaciona directamente con el bienestar $r s=0,253(p<0,001)$.

Como se observa, el estudio realizado arroja multitud de resultados los cuales pasamos a discutir a continuación.

\section{Discusión y conclusiones}

Los vídeos analizados recibieron más de 450 millones de visualizaciones durante el año 2014, lo que representa mil millones de minutos, o sea, 1.900 años visionando publicidad. Los anuncios presentan la estructura clásica (trama-nudo-desenlace) con una duración superior a la habitual (medía 2'21", SD =1'30"). En este sentido encontramos diferencias respecto a la publicidad televisiva tradicional, la cual establece duraciones entre los $10 \mathrm{y}$ los 120 segundos (Escribano, Fuentes \& Alcaraz, 2007; Peters \& Bijmolt, 1997; Prado et al., 2007), de forma que se nos plantea cierta dificultad a la hora de denominar la publicidad que se usa habitualmente en YouTube, derivando hacia nuevas clasificaciones que abracen e integren conceptos clásicos, como el del spot publicitario y filme publicitario (Gutiérrez, 2005) dentro de las nuevas plataformas (Draganska, Hartmann \& Stanglein, 2014).

Respecto a la música usada en los anuncios, los resultados coinciden con los estudios de Palencia-Lefler (2010) sobre la publicidad en televisión, donde afirmaba que el 50 por ciento de la música que se usaba en publicidad era preexistente. En este sentido, tal como describe Klein (2013) podemos constatar cómo los estilos 


\section{ARTÍCULOS DE INVESTIGACIÓN}

de música "moderna" (rock, pop, jazz...), presentes en seis de nuestros anuncios analizados, son los más usados en publicidad. En el caso de la música clásica, y coincidiendo con Jorgensgaard (2015) se alude mayoritariamente al carácter épico de la banda sonora, de forma que contagia al espectador el ritmo y la emoción propias de una película de aventuras. En cualquier caso, todos los anuncios usaron música de compás binario (Szymanski \& Hise, 2000), como es habitual en todos estos estilos musicales.

Respecto a los resultados obtenidos en las caracterizaciones emocionales, tal como podemos observar en la figura 2 donde aparecen las 310 respuestas, la característica principal sería su dispersión (rango de activación entre 7.38 y 3.73; rango de bienestar entre 8.73 y 5.10). A pesar de esto se aprecia cierta tendencia hacia el cuadrante de mayor activación y bienestar en los potenciales consumidores (medias 6.18 y 6.61, respectivamente), aunque de forma moderada. Esto coincide con lo señalado por Bruner y Kumar (2000) en estudios previos sobre la publicidad en Internet que señalan la preferencia por hacer de la publicidad audiovisual un producto complaciente y que motive cierto interés, pues ese punto medio entre el bienestar y el malestar es el que más incita al consumo (Bruner, 1990).

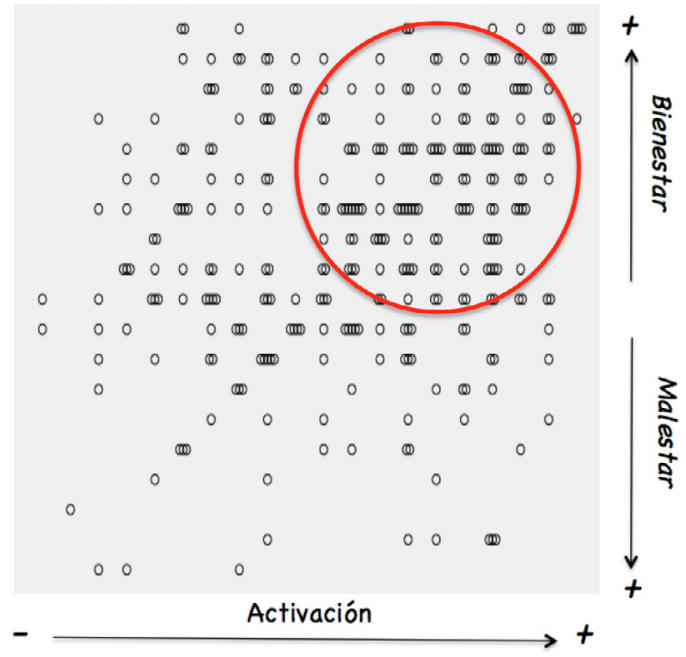

Figura 2: Dispersión de los resultados obtenidos en la caracterización emocional 
En este sentido, y refiriéndonos exclusivamente al parámetro de la activación, los datos obtenidos muestran un desigual comportamiento en cada vídeo. Así pues, podemos observar tres tendencias claras: por un lado, los vídeos que en el momento de la audición sola puntuaron más bajo que en las otras dos fases $\left(n^{0} 3,4,6\right.$ y 8); los que marcaron más alto en la fase de la audición que en el resto (vídeos 1, 2, 7,9 y 10); y un vídeo que no se comportó como los anteriores ( $n^{0} 7$ ) (ver figura 3 ).

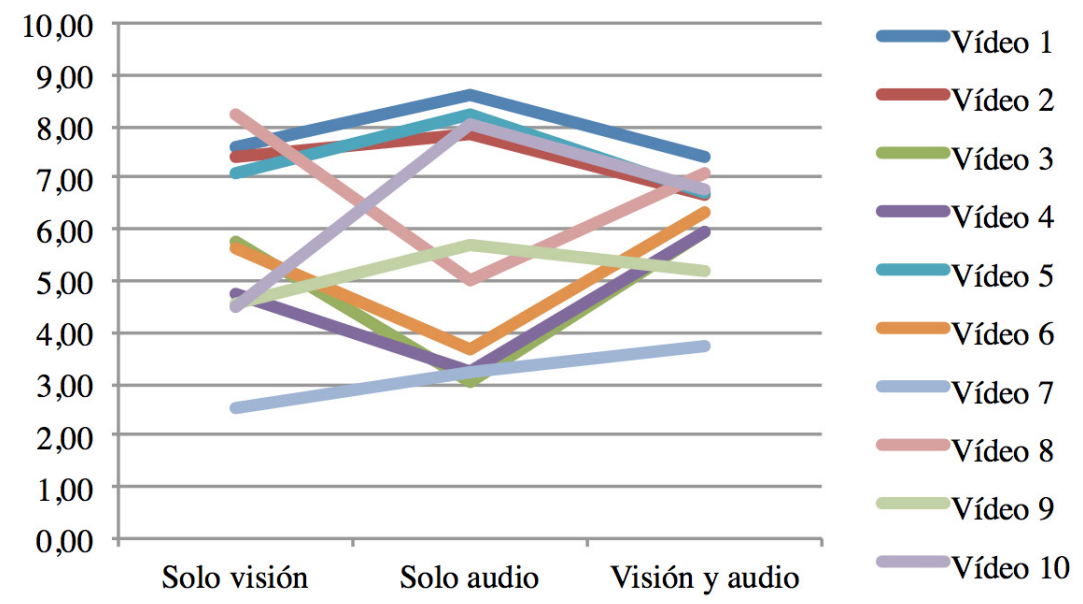

Figura 3: Puntuaciones de cada vídeo según la activación

Tanto en el visionado con audición como sin ella, observamos cómo los vídeos que puntuaron más alto en activación fueron los relacionados con deportes $\left(n^{0} 1\right.$, 2,6 y 8) y el que tenía como tema central el miedo (vídeo 5). Para ello, en el caso del deporte, además de la temática en sí (Horne, 2006), sin duda los movimientos rápidos de cámara y la sucesión de imágenes colaboraron en conseguir una mayor activación en el público.

Sin embargo, en el caso de la audición sin imágenes, observamos cómo los vídeos que usaron música con tempos más rápidos, son los que puntuaron más altos en activación ( $n^{0} 1,2,5$ y 10). Este aspecto está ampliamente estudiado en la literatura musical, donde se ha demostrado que prácticamente todas las culturas reaccionan de forma similar a los diversos tempos musicales (Phillips-Silver \& Trainor, 2007). Por el contrario, el vídeo que obtuvo la puntuación más baja, el $n^{0} 4$, es el que tenía menos música y a menor volumen que los diálogos. 


\section{ARTÍCULOS DE INVESTIGACIÓN}

Por lo que respecta al bienestar, y tal como podemos observar en la figura 4, encontramos dos tendencias: los vídeos que puntuaron más bajo en la audición sola que en el resto de parámetros $\left(n^{0} 1,2,3,4,5,6,8\right.$ y 10); y los que puntuaron más alto en la fase de audición ( $n^{0} 7$ y 9 ) (ver figura 4 ).

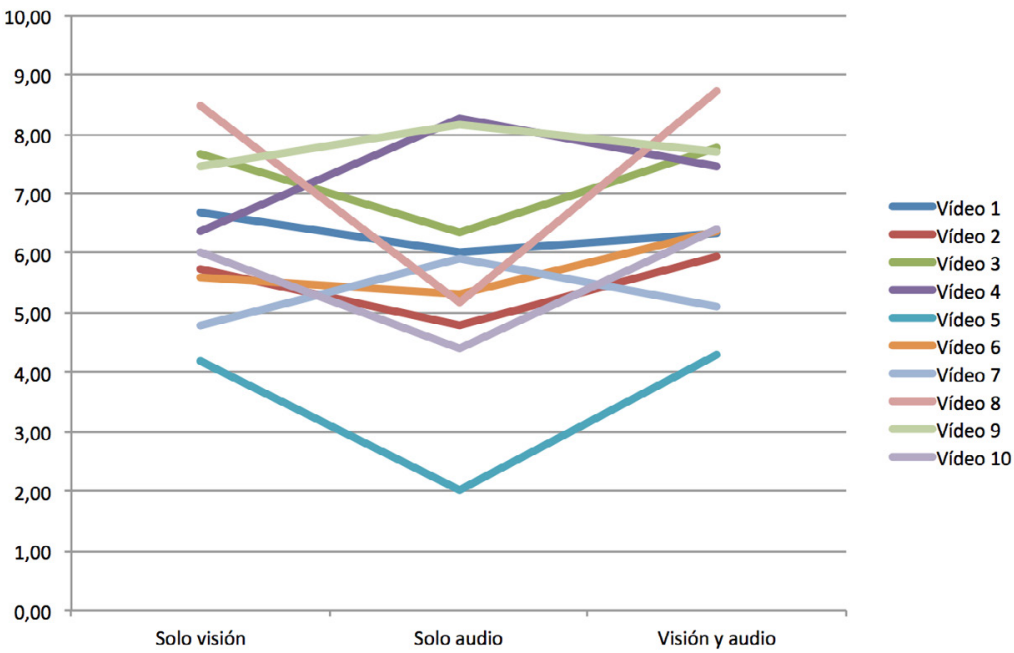

Figura 4: Puntaciones de cada vídeo según el bienestar/malestar

Este dato nos invita a pensar que, en la mayoría de los casos, el bienestar en la audición sin visión puntuó menos que el resto de las fases. Como no hemos hallado coincidencias en las características de los vídeos, los analizaremos por separado. Así pues, comprobamos cómo los anuncios que puntuaron más alto en el visionado sin audio o con audio, son los que apelaban a valores familiares (vídeo 8) y los que tenían a mascotas -concretamente perros- como protagonistas $\left(n^{0} 3,8\right.$ y 9). A pesar de las diferencias culturales, estos datos confirman las hipótesis sobre la influencia matriarcal en la publicidad estadounidense (Robinson \& Hunter, 2008), o del uso habitual de perros en la publicidad (Stone, 2014) para acentuar las características de ternura (Phillips, 1996).

En el caso del audio, observamos cómo los vídeos que puntuaron sustancialmente más alto son los que usaron música de estilo pop (vídeos 4 y 9). Este dato puede estar condicionado a la edad de los jueces, todos ellos estudiantes uni- 
versitarios, con hábitos de consumo musical más cercanos a este estilo (North, Hargreaves \& $\left.0^{\prime} \mathrm{Neill}, 2000\right)$. Llama la atención cómo cuatro de los vídeos ( $\mathrm{n}^{0} 2$, 3,5 y 10) puntuaron en la audición sin imágenes, en la zona de malestar, a pesar de tener características musicales y sonoras muy diferentes. El vídeo 5 es el que puntuó más bajo en bienestar en todas las fases, pues se trataba de un vídeo que promociona una película de terror.

Es destacable cómo el vídeo que obtuvo algunas de las puntuaciones más bajas en todos los aspectos, el $n^{0} 7$, es el que tenía como protagonista un teléfono móvil, a pesar de los esfuerzos de las compañías por implementar el uso de estos dispositivos en edades cada vez más tempranas (Duek, Enriz, Tourn \& Larreta, 2012).

Respecto a los jueces, tal como hemos visto, y a excepción de la audición del spot 4, no se apreciaron diferencias estadísticas en los resultados en función del género. Así pues, podemos afirmar que los anuncios más exitosos, más allá de la temática que aborden, están diseñados para gustar tanto a hombres como a mujeres.

En la visión sin audición, podemos observar cómo los anuncios en los que se apreció una correlación positiva entre activación y bienestar $\left(n^{0} 1,6\right.$ y 10) no presentan características visuales comunes.

En la audición sin visionado, los vídeos que mostraron correlación positiva entre bienestar y activación fueron el vídeo $1(r s=, 542 ; p=0,002)$ y el $2(r s=0,390 ; p=$ 0,030); ambos publicitaban la misma marca deportiva y usaban aplausos y sonidos de espectadores como fondo de una canción rock preexistente. Por el contrario, los vídeos 4 ( $r s=-0,391 ; p=0,030), 5(r s=-0,368 ; p=0,041)$ y $8(r s=-0,722 ; p$ $<0,001)$ mostraron una correlación negativa entre bienestar y activación. En el caso del vídeo 8 , debemos tener presente el sonido de las múltiples caídas en la primera parte, lo que sin duda condicionó la sensación de bienestar general. En el caso del vídeo 5, el estilo trash metal de su música produjo mucha activación con un malestar muy marcado, lo cual contribuye a la idea de que, en el terror, la imagen complementa al sonido para obtener lo que Marimón (2013) describía como el "bienestar del malestar". En el caso del vídeo 4, ocurrió lo contrario: una música 


\section{ARTÍCULOS DE INVESTIGACIÓN}

pop de tempo relajado con un final con carácter épico produjo una baja activación, pero un gran bienestar.

En la visión con audición, podemos observar cómo todos los anuncios que correlacionaron lo hicieron de forma directa: vídeos 1 ( $r s=0,543 ; p=0,002), 2$ (rs $=0,527 ; p=0,002), 6(r s=0,456 ; p=0,010), 8(r s=0,415 ; p=0,020)$ y $10(r s$ $=0,569 ; p=0,001)$. En todos los casos, a excepción del 10, los anuncios estaban centrados en los deportes, por lo que la música, sin ser del mismo estilo ni tempo, parece acentuar la activación que las imágenes producen.

Como conclusión, y en función de los resultados obtenidos, podemos afirmar que en la publicidad en YouTube no existe una formula fija que asegure el éxito, ya que, como hemos podido observar, la dispersión de los resultados, el comportamiento parecido de anuncios con características diferentes y el distinto comportamiento de anuncios con características similares, no plantea una línea a seguir que asegure el éxito de un spot. A pesar de ello, hemos encontrado aspectos comunes, como su duración, que distingue estos anuncios de la publicidad televisiva. En cualquier caso y analizando los resultados generales mostrados en la tabla 2, en los anuncios más vistos en el canal de YouTube en 2014 la activación del espectador dependería más de la música que acompaña al spot, mientras que el bienestar dependería más de las imágenes, dato que concuerda con el trabajo de Caballero-Meneses y Menez (2010). Además, hemos comprobado que el canal visual prima respecto al auditivo. En cualquier caso, tanto en la visión sin audición, como en la audición sin visión, o el visionado con el audio, existe correlación entre la activación y el bienestar. De la misma forma, tal como muestran estudios previos, la conjunción de imagen y música acentúa la sensación de activación y de bienestar (Gustems, Calderón \& Calderón, 2016).

Sin duda, la publicidad inunda nuestras vidas entrando en los canales destinados al ocio y adaptándose a los nuevos medios, como YouTube. A pesar de este proceso de adecuación, sus características tradicionales continúan estando presentes, por lo que no creemos que, al menos de momento, podamos hablar de nuevas formas de marketing, sino simplemente de nuevas formas de llegar a los consumidores. 


\section{Referencias}

Acaso, M. (2006). Esto no son las Torres Gemelas. Cómo aprender a leer la televisión y otras imágenes. Madrid: Catarata.

Acaso, M. (2009). La educación artística no son manualidades. Nuevas prácticas en la enseñanza de las artes y la cultura visual. Madrid: Catarata.

Bandler, R. \& Grinder, J. (1982). De sapos a príncipes: programación neurolingüística. Santiago de Chile: Cuatro vientos.

Bañuelos, J. (2009). Youtube como plataforma de la sociedad del espectáculo.

Razón y palabra, 69, 87. Recuperado de https://goo.gl/YXD0AG

Bruner, G. C. (1990). Music, Mood, and Marketing. Journal of Marketing, 54(4), 94104. D0I: $10.2307 / 1251762$

Bruner, G. C. \& Kumar, A. (2000). Web commercials and advertising hierarchy-of-effects. Journal of Advertising Research, 40(1-2), 35-42. D0I: 10.2501/JAR-40-1-2-35-42

Caballero-Meneses, J.A. \& Menez, M. (2010). Influencia del tempo de la música en las emociones. Revista Colombiana de Psicología, 19(1), 1-12. Recuperado de https://goo.gl/byAV3H

Camarero, G. (2009). Pintores en el cine. Madrid: Ediciones JC.

Collelldemont, E. (2008). Retos y dificultades de educar la sensibilidad ante los medios audiovisuales y literarios. Estudios sobre Educación, 14, 45-61. Recuperado de https://goo.gl/Gvo1dV

Diener, E. \& Emmons, R. A. (1984). The independence of positive and negative affect. Journal of Personality and Social Psychology, 47(5), 1105-1117. Recuperado de https://goo.gl/GtwliW

Duek, C., Enriz, N., Tourn, G. \& Larreta, F. M. (2012). Niños, teléfonos móviles y consumo: nuevas prácticas con nuevas tecnologías. Infancias Imágenes, 11(1), 9-17. Recuperado de https://goo.gl/6Jt1Nj

Draganska, M., Hartmann, W. R. \& Stanglein, G. (2014). Internet versus television advertising: A brand-building comparison. Journal of Marketing Research, 51(5), 578-590. DOI: 10.1509/jmr.13.0124

Eder, J. (2008). Feelings in conflict: A Clockwork Orange and the explanation of audiovisual emotions. Projections, 2(2), 66-84. D0I: 10.3167/proj.2008.020205

Escribano, G. Fuentes, M. \& Alcaraz, J. (2006). Políticas de marketing. Madrid: Paraninfo. 


\section{ARTÍCULOS DE INVESTIGACIÓN}

Fraile, T. (2012). Músicas para persuadir. Apropiaciones musicales e hibridaciones genéricas en la publicidad audiovisual. Revista Comunicación, 10(1), 324-337. Recuperado de https://goo.gl/8egxjU

Gustems, J. (2005). Escuchar los anuncios: una aproximación al uso de la música y del sonido en la publicidad televisiva. Eufonia, 34, 91-100.

Gustems, J. \& Calderón, C. (2014a). Música y publicidad audiovisual. In J. Gustems (Ed.), Música y audición en los géneros audiovisuales (pp. 143-154). Barcelona: Publicacions i Edicions de la Universitat de Barcelona.

Gustems, J. \& Calderón, C. (2014b). El análisis multimodal en la escucha de los audiovisuales. In J. Gustems (Ed.), Música y Audición en los Géneros Audiovisuales (pp. 15-28). Barcelona: Publicacions i Edicions de la Universitat de Barcelona.

Gustems, J., Calderón, C. \& Calderón, D. (2016). Análisis multimodal: una herramienta al servicio de la educación visual. Harvard Deusto, 7, 12-17.

Gutiérrez, P. (2005). Diccionario de la Publicidad. Madrid: Editorial Complutense. Horne, J. (2006). Sport in consumer culture. Londres: Palgrave Macmillan.

Jorgensgaard, N. (2015). Analizing Music in Advertising. Television Commercials and Consumer Choice. Nueva York: Routledge.

Juslin, P. N. \& Sloboda, J. A. (2001). Music and emotion: Theory and research. 0xford: 0xford University Press.

Kress, G. \& van Leeuwen, T. (2001). Multimodal discourse. The modes and media of contemporary Communication. Londres: Edward Arnold.

Klein, B. (2013). As heard on TV: Popular music in advertising. Burlington: Ashgate. Larrañaga, J. \& Ruiz, A. (2009). El modelo de negocio de Youtube. Revista Icono14, 12, 109-131. Recuperado de https://goo.gl/IkJmYS

Lavado, A. (2013). El consumo de Youtube en España. Global Media Journal México, 7(14) 76-92. Recuperado de https://goo.gl/4vXj8s

Lipman, M. \& Sharp, A. M. (1996). Admirant el món. Manual d'instruccions per acompanyar el KIO y GUS. Vic: Eumo.

Madinaveitia, E. (2010). La publicidad en medios interactivos: en busca de nuevas estrategias. Telos: Cuadernos de comunicación e innovación, 82, 43 -54. Recuperado de https://goo.gl/QXkdgk

Marimon, J. (2013). El bienestar del malestar: el placer por el cine de terror. In J. Gustems (Ed.), Arte y Bienestar (pp. 139-149). Barcelona: Publicacions i Edicions de la Universitat de Barcelona. 
Messaris, P. (1994). Visual" literacy": Image, mind, and reality. Colorado: Westview Press.

Nardone, G. \& Salvini, A. (2006). El diálogo estratégico. Barcelona: RBA.

North, A. C., Hargreaves, D. J. \& 0'Neill, S. a. (2000). The importance of music to adolescents. British Journal of Educational Psychology, 70(2), 255-272. Recuperado de https://goo.gl/KWKzki

Oliva, C. (2012). Comunicación 2.0, visibilidad e interactividad: fundamentos de la imagen corporativa de las Universidades Públicas de Madrid en Youtube. Fonseca, Journal of Communication, 5, 117-139. Recuperado de https://goo.gl/gXp0w0

Palencia-Lefler, M. (2010). Banda sonora de la publicidad televisiva española: formas, géneros y estilos musicales. Comunicación y sociedad, 23(1), 299-318. Recuperado de https://goo.gl/UrY08G

Percy, L. \& Rosenbaum-Elliott, R. (2016). Strategic advertising management. 0xford: Oxford University Press.

Peters, R. G. \& Bijmolt, T. H. (1997). Consumer memory for television advertising: A field study of duration, serial position, and competition effects. Journal of Consumer Research, 23(4), 362-372. Recuperado de https://goo.gl/mDCqmo Phillips, B. J. (1996). Advertising and the cultural meaning of animals. NA-Advances in Consumer Research, 23, 354-360. Recuperado de https://goo.gl/qxGvIH Phillips-Silver, J. \& Trainor, L. J. (2007). Hearing what the body feels: Auditory encoding of rhythmic movement. Cognition, 105(3), 533-546. D0I: 10.1016/j. cognition.2006.11.006

Prado, E., Franquet, R., Ribes, F. X., Soto M. T. \& Fernández, D. (2007). La publicidad televisiva ante el reto de la interactividad. Questiones Publicitarias, 12(1), 1328. Recuperado de https://goo.gl/5WHcVG

Robinson, B. K. \& Hunter, E. (2008). Is mom still doing it all? Reexamining depictions of family work in popular advertising. Journal of Family Issues, 29(4), 465-486. Recuperado de https://goo.gl/UA0r6o

Russell, J. A. (1980). A circumplex model of affect. Journal of Personality and Social Psychology, 39, 1161-1178. Recuperado de https://goo.gl/zuBFhq

Sánchez Porras, M. J. (2013). La persuasión de la música en la publicidad. El ejemplo Coca-Cola. Historia y Comunicación Social, 18, 349-357. D0I: 10.5209/ rev_HICS.2013.v18.44333 


\section{ARTÍCULOS DE INVESTIGACIÓN}

Santacreu Fernández, 0. A. (2002). La música en la publicidad. Alicante: Universidad de Alicante. Recuperado de https://goo.gl/BxdeVL

Schubert, E. (1999). Measuring emotion continuously: Validity and reliability of the two-dimensional emotion-space. Australian Journal of Psychology, 51(3), 154-165. DOI: 10.1080/00049539908255353

Sedeño, A. (2011). La música en los comerciales televisivos: el arma secreta. Sinfonía virtual, 18. Recuperado de https://goo.gl/EeTdIs

Stone, S. M. (2014). The Psychology of Using Animals in Advertising. En Hawaii University International Conferences Arts, Humanities \& Social Sciences. Recuperado de https://goo.gl/7qlufw

Szymanski, D. M. \& Hise, R. T. (2000). E-satisfaction: an initial examination. Journal of Retailing, 76(3), 309-322. DOI: 10.1016/S0022-4359(00)00035-X Villafañe, J. (2006). Introducción a la teoría de la imagen. Madrid: Pirámide.

Vines, B. W., Krumhansl, C. L., Wanderley, M. M. \& Levitin, D.J. (2006). Crossmodal interactions in the perception of musical performance. Cognition, 101, 80-113. DOI: 10.1016/j.cognition.2005.09.003

\section{Agradecimientos}

Este trabajo ha sido financiado mediante las Ayudas de la Agrupación en Investigación en Ciencias de la Educación, Universidad de Barcelona (A.R.C.E., convocatoria 2015). 